\title{
Comparison of hydrophile-lipophile balance of glycerol, DMGP, and DOP with the activity coefficient of water at infinite dilution in the compound
}

Citation for published version (APA):

Mierlo, van, P. P., \& Stein, H. N. (1989). Comparison of hydrophile-lipophile balance of glycerol, DMGP, and DOP with the activity coefficient of water at infinite dilution in the compound. Journal of Colloid and Interface Science, 127(2), 583-585. https://doi.org/10.1016/0021-9797(89)90063-5

DOI:

10.1016/0021-9797(89)90063-5

Document status and date:

Published: 01/01/1989

Document Version:

Publisher's PDF, also known as Version of Record (includes final page, issue and volume numbers)

\section{Please check the document version of this publication:}

- A submitted manuscript is the version of the article upon submission and before peer-review. There can be important differences between the submitted version and the official published version of record. People interested in the research are advised to contact the author for the final version of the publication, or visit the $\mathrm{DOI}$ to the publisher's website.

- The final author version and the galley proof are versions of the publication after peer review.

- The final published version features the final layout of the paper including the volume, issue and page numbers.

Link to publication

\footnotetext{
General rights

- You may freely distribute the URL identifying the publication in the public portal. follow below link for the End User Agreement:

www.tue.nl/taverne

\section{Take down policy}

If you believe that this document breaches copyright please contact us at:

openaccess@tue.nl

providing details and we will investigate your claim.
}

Copyright and moral rights for the publications made accessible in the public portal are retained by the authors and/or other copyright owners and it is a condition of accessing publications that users recognise and abide by the legal requirements associated with these rights.

- Users may download and print one copy of any publication from the public portal for the purpose of private study or research.

- You may not further distribute the material or use it for any profit-making activity or commercial gain

If the publication is distributed under the terms of Article 25fa of the Dutch Copyright Act, indicated by the "Taverne" license above, please 


\section{Comparison of Hydrophile-Lipophile Balance of Glycerol, DMGP, and DOP with the Activity Coefficient of Water at Infinite Dilution in the Compound}

\section{INTRODUCTION}

Characterization of the "polarity" of an organic medium by an exactly measurable quantity is interesting in such fields as the stability of dispersions in organic media, emulsion stability, etc. Very often, a rather crude "rule of thumb" is employed: the hydrophilic/lipophilic balance (HLB) value (1). Szymanowski and Beger (2) define the polarity index of a compound on the basis of gas chromatographic data (retention volumes), as

$$
P I=100 \log (C-4.7)+60
$$

where $P I$ is the polarity index and $C$ is the apparent number of carbon atoms in a standard alkane having the same retention as the compound concerned. Establishing a value for $C$ requires retention data not only of the component under study, but also of $n$-alkanes.

Although a high correlation between $P I$ and HLB is found we propose that it is much more straightforward to compare the HLB to a thermodynamic quantity, viz., the activity coefficient of water at infinite dilution in the compound, $\gamma^{\circ} \mathrm{H}_{2} \mathrm{O}$. This activity coefficient can be derived from gas chromatography (3). The choice to use the activity coefficient at infinite, rather than at some intermediate, dilution is based upon the fact that water has very low solubility in many of the components under study.

Alternatively, the HLB of a substance may be related to the distribution constant of the substance between water and a nonpolar solvent, e.g., decane. In this respect the HLB would be determined by the activity coefficient of the substance at infinite dilution in water, as well as by its activity coefficient at infinite dilution in the apolar medium. It is, however, interesting to investigate if a simple correlation with $\gamma^{\circ} \mathrm{H}_{2} \mathrm{O}$ may suffice.

Below we will compare the HLB to $\gamma^{\circ} \mathrm{H}_{2} \mathrm{O}$ at $298 \mathrm{~K}$ and other temperatures in glycerol, di (methoxy-glycol)phthalate (DMGP), and di(2-ethyl-hexyl)-phthalate (DOP). These compounds have been used as media with varying degrees of hydrophility in studies of coagulation (4).

\section{METHODS}

Stainiess steel columns ( $2 \mathrm{~mm}$ inner diameter, $2 \mathrm{~m}$ long) were filled with packings containing various loadings of glycerol, DMGP, and DOP. It is necessary to vary the liquid loading to be able to rule out concurrent contributions to retention (5). Concurrent retention mechanisms are ruled out by extrapolating retention data to infinite liquid loading, whereupon the activity coefficients of the injected solute follow from (6)

$$
\ln \gamma=\ln \frac{R T}{p_{1}^{\mathrm{o}} \mathrm{v}_{\mathrm{L}} K_{\mathrm{L}}}-\frac{B_{11} p^{\circ}}{R T}
$$

where $K_{\mathrm{L}}$ is the partition coefficient of the solute in the stationary phase, defined as the ratio of molarities of the solute in the gas and the liquid phase, at equilibrium. $K_{\mathbf{L}}$ is equal to the ratio $V_{\mathrm{N}} / V_{\mathrm{L}}$ extrapolated to infinite loading; $V_{\mathrm{N}}$ is the net retention volume; $V_{\mathrm{L}}$ is the stationary phase loading of the column; $v_{\mathrm{L}}$ is the molar volume of the stationary phase; $p_{i}^{0}$ is the saturated vapor pressure of the solute at column temperature; $\boldsymbol{B}_{11}$ is the second virial coefficient of the solute vapor.

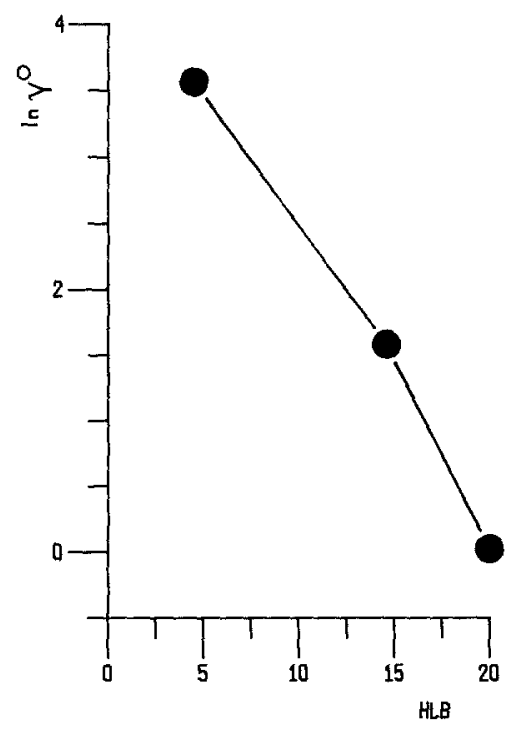

FIG. 1. Plot of the activity coefficient of water at infinite dilution in glycerol, DMGP, and DOP extrapolated to 298 $K$ versus the HLB value of the media. 
TABLE I

Partition Coefficients and Activity Coefficients of Water at Infinite Dilution in Glycerol, DMGP, and DOP

\begin{tabular}{lllrrr}
\hline Liquid phase & $\left.T{ }^{\circ} \mathrm{C}\right)$ & $p^{\circ}(\mathrm{atm})$ & $K_{\mathrm{L}}$ & $B\left(\mathrm{~cm}^{3} / \mathrm{mole}\right)$ & $\ln \gamma^{\circ} \mathrm{H}_{2} \mathrm{O}$ \\
\hline DOP & 60 & 0.199 & 18.7 & -0.690 & 2.935 \\
DOP & 70 & 0.312 & 14.5 & -0.614 & 2.776 \\
DOP & 80 & 0.473 & 12.4 & -0.551 & 2.547 \\
DOP & 90 & 0.701 & 8.9 & -0.496 & 2.513 \\
DMGP & 60 & 0.199 & 155.9 & -0.690 & 1.314 \\
DMGP & 70 & 0.312 & 109.3 & -0.614 & 1.250 \\
DMGP & 80 & 0.473 & 80.5 & -0.551 & 1.171 \\
DMGP & 90 & 0.701 & 58.3 & -0.496 & 1.131 \\
GLY & 60 & 0.199 & 2126.4 & -0.690 & -0.106 \\
GLY & 70 & 0.312 & 1400.6 & -0.614 & -0.107 \\
GLY & 80 & 0.473 & 1009.7 & -0.551 & -0.165 \\
\hline
\end{tabular}

Note. For the meaning of the symbols refer to Eq. [2] in the text.

Note that $\ln \gamma$ is based here upon the so-called symmetrical convention, where $\mu=\mu^{\circ}+R T \ln \gamma$, with $\mu$ the chemical potential of the compound, $x$ the mole fraction, and $\mu^{\circ}$ the chemical potential of the pure compound.

We found that it is not necessary to include a correction term for carrier gas nonideality in Eq. [2].

\section{MATERIALS}

Glycerol was obtained from Merck, Darmstadt (grade Wasserfrei, Reinst 98-100.5\%), and DMGP and DOP from Fluka, Ag, Buchs, $>98$ and $>99 \%$, respectively. All compounds were used without further purification.

\section{RESULTS AND DISCUSSION}

Table I lists the values of the activity coefficients obtained from the GLC measurements. Using the following well-known relationship (7) activity coefficients at $298 \mathrm{~K}$ were calculated.

\section{TABLE II}

Activity Coefficients of Water at Infinite Dilution at $298 \mathrm{~K}$ and HLB Values

\begin{tabular}{lll}
\hline Medium & HLB & In $\gamma_{298}$ water \\
\hline Glycerol & 20 & 0.02 \\
DMGP & 14.6 & 1.58 \\
DOP & 4.5 & 3.56 \\
\hline
\end{tabular}

$$
\ln \gamma_{i^{\circ}, T}=\ln \gamma_{i^{\circ}, T=T_{\mathrm{ref}}}+\frac{H_{i}^{E}}{R}\left(\frac{1}{T}-\frac{1}{T_{\mathrm{ref}}}\right)
$$

where $\gamma_{i, T}^{\circ}$ is the activity coefficient of component $i$ at infinite dilution, temperature $T ; H_{i}^{E, 0}$ is the excess partial molar enthalpy of component $i$ at infinite dilution (assumed here to be independent of temperature); $T_{\text {ref }}$ is a reference temperature.

Table II lists the activity coefficient of water at infinite dilution at $298 \mathrm{~K}$ as well as the HLB values of the media under study (taken from Ref. (4)). Figure 1 is a plot of the activity coefficient versus the HLB value. It is seen that there is a high degree of correlation between the quantities, where $\ln \gamma^{\circ}$ decreases as the HLB increases. This is readily understood by realizing that an increase in HLB indicates a more hydrophilic medium, more compatible with water, and thus yielding an activity coefficient closer to unity. In order to establish the possible existence of a linear relationship between $\ln \gamma^{\circ} \mathrm{H}_{2} \mathrm{O}$ and HLB we feel that more data are needed.

\section{CONCLUSIONS}

The activity coefficient of water at infinite dilution in a medium may very well serve as a less arbitrary measure of the polarity of the medium than is the HLB, because the activity coefficient is based directly upon measurement. Also, it is more straightforward to use the activity coefficient and less data are required than, e.g., for the polarity index. Preliminary investigations indicate a high degree of correlation between the activity coefficient of water at infinite dilution and the HLB, but more data are needed to establish whether a linear relationship exists. 


\section{REFERENCES}

1. Shinoda, K., and Kunieda, H., in "Encyclopedia of Emulsion Technology" (P. Becker, Ed.), Vol. 1, Chap. 5. Dekker, New York, 1983.

2. Szymanowski, J., and Beger, J., J. Colloid Interface Sci. 119, 286 (1987).

3. Conder, J. R., and Young, C. L., "Physicochemical Measurement by Gas Chromatography," Chap. 5. Wiley, Chichester, 1979.

4. van Diemen, A. J. G., Schreuder, F. W. A. M., and Stein, H. N., J. Colloid Interface Sci. 104, 87 (1985).

5. Conder, J. R., and Young, C. L., "Physicochemical
Measurement by Gas Chromatography," p. 494. Wiley, Chichester, 1979.

6. Martire, D. E., Anal. Chem. 38, 245 (1966).

7. Smith, J. M., and van Ness, H. C., "Introduction to Chemical Engineering Thermodynamics," 3rd ed., p. 269. McGraw-Hill, Tokyo, 1959.

P. P. VAN MIERLO HANS N. STEIN

Laboratory of Colloid Chemistry,

Eindhoven University of Technology,

Eindhoven, The Netherlands

Received December 7, 1987; accepted March 24, 1988 